\title{
ANTONIO «DE MALINAS», UN ESCULTOR DE LOS PAÍSES BAJOS EN LA ESPAÑA DEL RENACIMIENTO
}

\author{
POR \\ FELIPE PEREDA \\ Universidad Autónoma de Madrid
}

Para José Ramón Campos

La construcción de la Catedral Nueva de Salamanca atrajo hasta la ciudad del Tormes a un importante grupo de escultores entre los cuales destacan los nombres de varios imagineros procedentes de los Países Bajos. Gracias a los Libros de Fábrica se ha podido identificar la importante labor de un cierto Antonio "de Malinas" cuya biografía española encaja sin dificultad con las noticias documentales que tenemos de Anthonis van Mansdale III alias Keldermans, un escultor que había abandonado su ciudad de origen hacia 151617, regresó fugazmente a su ciudad natal en 1523, y dejó la memoria de haber fallecido poco después durante la travesía que emprendió a su regreso desde España.

Palabras clave: Catedral Nueva de Salamanca. Anthonis van Mansdale III. Paises Bajos. Escultura. Renacimiento. Siglo XVI.

The construction of the New Cathedral of Salamanca attracted an important group of sculptors to the city on the Tormes, among whom the names of various artists from the Low Countries stand out. Thanks to the ledgers documenting the building, it has been possible to identify the significant work of a certain Antonio "de Malinas," whose Spanish biography coincides well with the documentary information we have for Anthonis van Mansdale III, known as Keldermans, a sculptor who left his native city around 1516-17, returned there briefly in 1523, and seems to have died shortly afterwards, during his return voyage from Spain.

Key words: New Cathedral of Salamanca. Anthonis van Mansdale III. Low Countries. Sculpture. Renaissance. $16^{\text {th }}$ Century.

Las relaciones artísticas y artístico-comerciales entre el Norte de Europa y Castilla, y más en concreto el extraordinario fenómeno de inmigración de maestros procedentes de los Países Bajos del Sur a partir de la segunda mitad del siglo xv, es una de las características más sobre-

* La búsqueda documental y bibliográfica de este trabajo fue posible gracias a una beca de investigación concedida por el Ministerio de Asuntos Exteriores para la residencia en Bélgica entre junio y septiembre de 1995. El presente ensayo constituye una reelaboración y puesta al día de uno de los capítulos de mi tesis doctoral, El artista, la imagen y su público en Salamanca, 1520-1525. Aproximación a una iconografía funcional, Universidad Autónoma de Madrid, 1996, dirigida por D.Alfonso Rodríguez G. de Ceballos. Agradecemos al señor Henri Installé, del archivo municipal de Malinas, la generosa ayuda prestada con la documentación. 
salientes de las artes, y muy en particular de la escultura de las dos Castillas, en la alta Edad Moderna ${ }^{1}$. En pocas ocasiones, sin embargo, resulta posible seguir documentalmente la biografía necesariamente azarosa de estos artistas desde su lugar de origen hasta su destino en alguno de los talleres donde se habían requerido su maestría.

El caso de Antonio «de Malinas», un imaginero documentado en Salamanca en 1523-24 entre los distintos escultores que fueron contratados para acometer la importante tarea decorativa de la Puerta del Perdón de la Catedral de Salamanca sería solo un nombre entre tantos otros imagineros con un catálogo precario, de no ser porque antes de partir hacia la Península Ibérica dejó a sus espaldas algunos interesantes documentos que nos permiten restituirle su verdadero origen y reconstruir con ello algunos datos de las expectativas de su viaje.

\section{Los imagineros en la Catedral de Salamanca}

Desde el comienzo de las obras de la Catedral de Salamanca el 13 de mayo del año $1513^{2}$, la fachada - el hastial del Perdón - había sido uno de los lugares que habían concentrado los intereses del cabildo. Como escribiera el obispo Juan de Castilla (13 de marzo de 1504), el deán y el cabildo habían decidido començar a edificar al revés. Es muy probable que en 1515 ya existiera una traza para el alzado de la portada ya que cuando los maestros Martín y Francisco de Colonia emitieron su informe acerca de la obra que bajo la maestría de Juan Gil de Hontañón se había realizado, sus observaciones testimonian el ritmo importante que llevaba la fábrica en su puerta oeste, donde ya se habían empezado a labrar algunas de las chambranas que tenían que cobijar las esculturas ${ }^{3}$, de lo que no sólo se deduce el buen ritmo que llevaba la obra, sino también que las «imágenes» se reservaban, como es lógico, para una segunda fase del trabajo.

Esta división de responsabilidades entre las obligaciones del taller del maestro cantero y la de los imagineros está perfectamente recogida en el contrato del destajo de Juan Gil de Hontañón el 14 de diciembre de 1520, donde quedaba encargado de la terminación de las tres puertas del hastial del Perdón ${ }^{4}$ así como de la que entonces llamaban «Puerta del taller» — por ser el lugar donde estaba ubicado el mismo- y que hoy conocemos como «Puerta de Ramos» ${ }^{5}$.

\footnotetext{
${ }^{1}$ Véase una introducción general al problema en el catálogo de la exposición Vlaanderen en Castilla y León, Amberes, 1995.

${ }^{2}$ Para los avatares de la construcción, de los que no podemos ocuparnos aquí, véanse fundamentalmente, Chueca Goitia, Fernando, La Catedral Nueva de Salamanca. Historia documental de su construcción, Salamanca, 1951. Casaseca Casaseca, Antonio, Las Catedrales de Salamanca, León, 1993. Castro Santamaría, Ana, Juan de Álava. Tesis doctoral inédita, 3 vols., Universidad de Salamanca, 1994. «Las visitas a la Catedral de Alava y Covarrubias en 1529 y de Egas y Bigarny en 1530 y sus consecuencias artísticas», Actas del Congeso de Medievalismo y Neomedievalismo. Las Catedrales de Castilla y León (I), Ávila, 1994, pp. 235-247; Juan de Álava. Arquitecto del Renacimiento, Salamanca, 2001, pp. 235-268. Gómez Martínez, Javier, «Maestría versus destajo en la Catedral de Salamanca», Ibid., pp.249-260; Rodríguez Gutiérrez de Ceballos, Alfonso, Las Catedrales de Salamanca, Everest, León, 1978; y Tormo, Elías, Salamanca: las Catedrales, Madrid, 1931.

${ }^{3}$ Así, en su informe los citados maestros hacían notar que: «... nos parece que en los encasamentos de las ymagines de los pilares se deben guardar mejor que oy dia estan guardados en algunas partes de los pilares de las portadas». ACSa, Libro de Pareceres, $\mathrm{n}^{\circ} 6$.

${ }_{4}$ «Yten que el dicho Juan Gil sea obligado por el dicho preçio de las dichas trezientas e ochenta myll mrs al hastial e muro de fuera todo lo tocante a las dichas capillas bien e perfetamente acabado en toda su perfiçion con todas sus gargolas e remates e claraboyas como a perfiçion de la dicha obra bien asi e tan perfetamente como si la yglesia del todo e por todo se acabase e fuese perfeta e acabada». ACSa, Libro de Pareceres, doc. $\mathrm{n}^{\circ} 5, \mathrm{f}^{\circ} 12$. Existe una segunda copia en el legajo de Actas Capitulares que se conserva en el AHN, Clero, Legajo, 5878, (fo 78-80), $\mathrm{f}^{\circ}$ 79. Extractado en: Chueca Goitia, F., Op. cit., pp. 42-44 y en Ana Castro, Op.cit., I., pp. 516-518.

${ }_{5}$ «Yten que el dicho Juan Gil sea obligado a acabar e dar acabada la puerta del taller con sus estribos conforme al ligimiento syn aver falta alguna lo qual a de ser acabado con todos sus remates a acabamiento por que cabe en alto de las dichas capillas la dicha puerta e los estribos que suben a lo alto e peso de los otros estribos los quales se an de subir conforme a los otros segund se requiere e que las pieças de la dicha portada sean tan labradas e linpias las que demas se
}

$A E A$, LXXVII, 2004, 306, pp. 139 a 157 
La exclusión de la imaginería en las portadas pudo haber sido una constante en los contratos con los canteros. Aunque no se especifica en lo concerniente a las puertas de la fachada oeste, lo más probable es que las condiciones fueran las mismas y que las esculturas bajo los encasamientos sólo fueran contratadas una vez se hubiera concluido la labor de cantería y talla de sillares. Tanto para las capillas, como para la Puerta de Ramos, la torrecilla y la Puerta del Perdón, el plazo estipulado del destajo fueron dos años ${ }^{6}$.

Resulta sorprendente, no obstante, la celeridad con la que el cabildo y el maestro mayor de la obra, el montañés Juan Gil de Hontañón, avanzaron en el diseño del imafronte. En 1522 ya se mandaba «trastejar» la fachada, lo que parece indicar que la obra en esta zona iba especialmente avanzada ${ }^{7}$. En concordancia con esto, el 8 de enero de 1523, Juan Gil recibió 3.750 maravedís por una traza ${ }^{8}$ que muy probablemente fuera para la Puerta del Perdón ${ }^{9}$ y un año más tarde (8-II-1524) le fue entregado un nuevo pago a cuenta de unas nuevas trazas «de las dichas portadas», muy probablemente un alzado de las tres puertas del hastial del oeste, por las que se le pagó la importante suma de ocho ducados, y a las que se le mandó «poner colores» ${ }^{10}$. Posiblemente este alzado de Juan Gil preveía ya la colocación e iconografía de la imaginería que iba a ser contratada de inmediato, pues es entre una y otra fecha cuando dan comienzo los pagos a los imagineros (a partir del 21-IV-1523) ${ }^{11}$, surgiendo en primer lugar la figura de Antonio de Malinas a quien, como veremos, se encomendó el grueso de las esculturas de la Puerta del Perdón, tarea que, por razones que desconocemos, no llevó completamente a término.

Los pagos a los «imaginarios» aparecen en las cuentas de fábrica de la Catedral de Salamanca desde abril de 1523 hasta septiembre de 1525, sin que en ningún momento -excepción hecha del encargo de Antonio de Malinas - se especifique el concepto por el que estaban cobrando. Los escultores que en condición de «imagineros» se documentan en la Catedral en esta primera y copiosa campaña fueron cinco $^{12}$ : en primer lugar, el citado Antonio de Malinas quien se documenta entre el 21 de abril de 1523 y el dos de mayo de 1524 cobrando un total de 5.084 maravedís. A continuación surge un cierto Domingo de Vidaña en 1524, desaparecido ya el anterior, y cobrando un total de 1.496 maravedís. Este mismo maestro volverá a aparecer más adelante, en 1526, pero lo hará como «entallador», muy posiblemente ocupándose de talla en madera. El tercer imaginero es el Maestro Gil de Ronça. Este último está registrado en los Libros de Cuentas en un lapso muy preciso de un año: desde el 26 de agosto de 1524

hizieren e labraren e asentaren como las que fasta agora estan hechas e asentadas eçeto que el dicho Juan Gil no ha de hazer ymajen ninguna en la dicha portada salvo encasamientos e pianas e çarmas las que mandaren los dichos señores $e$ a su voluntad», ACSa, Libro de Pareceres, $\mathrm{n}^{\circ} 5$.

${ }^{6}$ Ibid., $\mathrm{f}^{\mathrm{o}} 13$

${ }^{7} \mathrm{ACSa}$, Libro de Cuentas de Fábrica (1499-1539), fo 206. Castro, Ana, Op. cit., I, p. 517.

${ }^{8}$ «[Enero] A Juan Gil de la traza que hizo para la obra 3750 mrs». ACSa, Libro de Cuentas de Fábrica (1499-1539), $\mathrm{f}^{\circ}$ $221 v^{\circ}$.

${ }^{9}$ De esta opinión es Ana Castro, Op. cit., I, pp. 545-6.

10 «[8-II-1524] Como mandaron dar a Juan Gil e dar ocho ducados por la muestra de las portadas.

En Salamanca este dicho dia mes e año susodichos [...] el $\mathrm{Rvd}^{\circ}$ señor Provisor presento la traça e muestra de las dichas portadas an visto por el cabildo le mandaron poner colores otras muestras o traças de la dicha yglesia e le mandaron dar ocho ducados por della e por otros motivos que a ello le mobieron». ACSa, Actas Capitulares, $\mathrm{n}^{\circ} 26, \mathrm{f}^{\circ} 96 \mathrm{v}^{\circ}$. Cualquiera de las dos podría ser la que todavía Llaguno vio en el archivo de la catedral (Ed.cit., I, p. 152), aunque también ha sido identificada con alguna de las realizadas en 1529 en la visita de Juan de Álava y Alonso de Covarrubias, Castro, Ana, «Las visitas a la catedral de Salamanca...».

${ }^{11}$ A fines de 1522 ó comienzos de 1523 debe de corresponder una relación en la que se da cuenta de algunas piezas labradas para las portadas del hastial. Es el número 41 y último del «Libro de Pareceres» y lleva por encabezamiento: «Memoria de lo que esta labrado en la obra de Juan Gil» (ACSa, Libro de Pareceres, $\mathrm{n}^{\circ} 41$, ff. 65-65v $\mathrm{v}^{\circ}$ ). La relación debe situarse tras el regreso de Juan Gil a Salamanca el 4 de diciembre de 1522 e incluye numerosas piezas para dos de las capillas, para el caracol y numerosas labores para la portada como: «çinquenta e tres pieças rycas de la puerta las quales vtr ${ }^{\prime}$ mds pueden ver» $\mathrm{y}$ «XXV pieças de los estribos de las puertas de los pilares».

12 Vid. infra.

AEA, LXXVII, 2004, 306, pp. 139 a 157 
hasta septiembre de 1525 . Recibió el más cuantioso de los libramientos (53.437 maravedís) ${ }^{13}$, aunque es probable que parte de su trabajo haya que localizarlo no en el exterior del templo, sino en la Capilla Dorada que el arcediano Francisco Sánchez de Palenzuela compró precisamente aquel año y que requería una labor escultórica ingente ${ }^{14}$. Después de esta primera campaña el último escultor que con el nombre de «imaginero» aparece en las cuentas es Juan de Gante, pero no lo hará hasta 1530, varios años después de lo que hemos denominado «primera campaña» ${ }^{15}$

\section{Antonio de Malinas. Biografía}

La primera figura de la campaña de decoración de la Puerta del Perdón de la Catedral salmantina, al menos aquel en quien en un primer momento se había confiado la mayor parte de la imaginería, es un maestro conocido en nuestros archivos por su topónimo, Antonio «de Malinas» ${ }^{16}$. Según consta en los libros de Cuentas de fábrica fue a este escultor a quien se encargó la primera campaña de las esculturas exentas proyectadas para la fachada ${ }^{17}$. Así es como su nombre aparece por vez primera el 21 de abril de 1523:

Antonio de Malinas ymaginero $p^{a}$ cincuenta solas imagines que ha de hazer, quinze reales por libramiento a 21 de abril ${ }^{18}$.

Podemos suponer por lo tanto que se habría realizado un contrato con este imaginero en fechas inmediatamente anteriores, quizá a raíz de las nuevas trazas de Juan Gil de Hontañón. Con su ayuda quedaría clara la disposición y el número de las esculturas que tenían que realizarse, y las obras andarían lo suficientemente avanzadas como para que no corrieran peligro tras su colocación.

Desgraciadamente no es mucho más lo que sabemos de la actividad de Antonio de Malinas ${ }^{19}$ en la Península Ibérica. Su presencia tan sólo está documentada a lo largo de un año, hasta mayo de 1524, pero en dos momentos distintos separados por un largo paréntesis. Por otro lado, el total de los libramientos a su nombre suman una cifra a todas luces insuficiente para cubrir las cincuenta figuras que se obligaba a realizar. Ocho días después de recibir el encargo por las cincuenta esculturas, el 29 de abril cobró otros quince reales $\left(f^{\circ} 224 v^{\circ}\right)$; el 23

\footnotetext{
${ }^{13}$ Los pagos a Gil de Ronza alternan con los de su hijo Diego de Ronça — «Maestro Diego»—, quien formaría parte de su mismo taller.

${ }^{14}$ Hemos dedicado un capítulo de nuestra tesis a esta capilla. Véase además el trabajo Castro, Ana, «La Capilla Dorada de la Catedral Nueva de Salamanca», Comunicación presentada en el Congreso Medievalismo y Neomedievalismo. La Arquitectura y la Muerte. U.N.E.D., Ávila, 4-6 de octubre de 1991, agradezco a la autora la facilitación de su consulta; y A. Castro y J.C. Brasas Egido, Las Edades del Hombre. El contrapunto y su morada, Salamanca, 1993, n 55, pp. 117-122.

${ }^{15}$ Este imaginero aparece una única vez en los Libros de Cuentas. El 22 de Julio de 1531 «Juan de Gante ymaginario, de ymagines...» recibió 306 maravedís: ACSa, Libro de Cuentas de Fábrica (1499-1539), $\mathrm{f}^{\circ} 464 \mathrm{v}^{\circ}$. Por duplicado en $\mathrm{f}^{\circ}$ $485 v^{\circ}$. Chueca le atribuye el calvario de la portada, del cual únicamente sabemos que estaba labrado en 1537, ya que cuando ese año se decida levantar el tejado que cubría la portada se refieren a ella como la «puerta nueba del crucifijo» (Ibid., $f^{o}$ 711). Su estilo nos es desconocido. Todavía se encontraba en Salamanca el 13 de Noviembre de 1532 ya que ese año aparece como entallador vecino de la ciudad para reclamar once reales a Domingo de Azpeitia, cantero, por cierta obra no especificada que le había hecho: AHPSa, Protocolo, 3363, fo 593-593v $\mathrm{v}^{\circ}$. Probablemente se trata del escultor homónimo documentado en Sevilla, el cual el 6 de febrero de 1541 se obligaba a hacer unas andas de San Juan Bautista que un año después no había terminado de cobrar, dos años después cobraba por un tablón de talla de la Catedral de Sevilla y en 1554 recibía como aprendiz a un cierto Antonio de Arroyo, flamenco, natural de Gante, que no entendía el castellano: Gestoso y Pérez, op. cit., I, p. 104 y 184.

${ }^{16}$ Aunque en el interior de Brabante, Malinas constituía en realidad un pequeño enclave del Principado de Lieja.

${ }^{17}$ Pereda, Felipe. «La decoración escultórica de la Catedral de Salamanca en el siglo xvi», en Medievalismo y Neomedievalismo en la Arquitectura Española, Ávila, 1994, pp. 257-260.

${ }^{18}$ ACSa, Libro de Cuentas de Fábrica (1499-1539), $\mathrm{f}^{\circ} 224 \mathrm{v}^{\circ}$.

${ }^{19}$ Mantendremos de aquí en adelante la denominación «Antonio de Malinas», para evitar confusiones con los otros dos Antonios Keldermans de su misma familia.
}

$A E A$, LXXVII, 2004, 306, pp. 139 a 157 
de mayo de nuevo quince reales $\left(\mathrm{f}^{\mathrm{o}} 225 \mathrm{v}^{\circ}\right)$; el 21 de junio 1.500 maravedís de las ymagines que hizo ( $\left.f^{\circ} 226\right) ; 1.594$ maravedís el diez de julio y quince reales el último de julio ( $f^{\circ}$ 227). Su nombre desaparece entonces de los libros de cuentas para reaparecer casi nueve meses más tarde, recibiendo el 2 de mayo de 1524 un último pago de 850 maravedís de las arcas de la fábrica $\left(f^{\circ} 233 v^{\circ}\right)$. Pese al reducido monto total de estos pagos, existe un número de figuras aproximado al del encargo que responden a un mismo canon. Su calidad, sin embargo, es enormemente irregular, lo que puede explicarse, tanto por la colaboración de un taller, como porque el imaginero abandonó sin concluir su encargo, dejando que sus modelos fueran luego continuados por el resto de los escultores que entre 1524 y 1525 remataron la obra ${ }^{20}$.

Los datos arriba referidos de la intervención de un cierto Antonio «de Malinas» en Salamanca encajan sorprendentemente con las noticias documentales que tenemos de Anthonis van Mansdale III alias Keldermans, uno de los numerosos miembros de la conocida familia de canteros originarios de esa ciudad de los Países Bajos del Sur. En resumen: mientras que un escultor llamado Antonio Keldermans que había abandonado su ciudad de origen hacia 151617 , regresó fugazmente a su ciudad natal en 1523, dejando luego la memoria de haber fallecido poco después durante la travesía que emprendió a su vuelta desde España; mientras esto ocurría, un cierto «Antonio de Malinas» que se encontraba trabajando aquel mismo año en Salamanca, desapareció misteriosamente de la ciudad del Tormes semanas antes de que su vecino y tocayo reapareciera en los Países Bajos, volviendo después de un breve paréntesis a sumirse su recuerdo en el silencio documental. El engarce de ambas biografías hace bastante razonable la hipótesis de que se trata de los fragmentos separados de la vida de una sola persona. Esta es la teoría que defiende el presente artículo.

Además de la reciente monografía sobre la actividad arquitectónica de los Keldermans, en la cual se presta atención a los dos emigrantes de la familia ${ }^{21}$, la única biografía que se le ha dedicado es muy breve y la recogió Alexander Neeffs en su historia de la pintura y escultura de Malinas que escribió en el siglo XIX ${ }^{22}$. A este estudio hay que sumar las referencias que da R. de Roo sobre la documentación que se encuentra en el Stadsarchief de Mechelen donde se proporcionan las signaturas de los documentos lo que nos ha permitido la consulta de algunas de las fuentes en que se basa este estudio ${ }^{23}$.

No conocemos su fecha de nacimiento, como tampoco los detalles de su formación artística, pero todo apunta a que los primeros pasos en la escultura los daría de la mano de su padre, (activo al menos éste hasta 1525) como era costumbre en la tradición familiar. Antonio III Keldermans nació en el seno de una familia que llevaba cinco generaciones dedicándose a la arquitectura y la escultura. Era hijo del escultor Matthijs II y de Elisabeth van Horenbeke ${ }^{24}$ pero la dinastía de artistas se remontaba a su tatarabuelo, Jan I van Mansdale († 1424/25), también llamado Kelderken, nombre que con el tiempo se transformaría en el de Keldermans que adoptaron sus descendientes ${ }^{25}$. Sus únicos trabajos conocidos son como escultor, especialmente la Tumba de Margarita van Brieg. Dando comienzo a una costumbre que no se rompió en los cien años siguientes, su bisabuelo Jan II († 1445) se formó en el taller de su padre, trabajando lo mis-

\footnotetext{
${ }^{20}$ La razón por la cual todos los libramientos no se registraron en el libro de Cuentas es para nosotros una incógnita, pero al no haberse conservado ninguno de los contratos que realizaron estos maestros, desconocemos los términos en los que tenían que satisfacerse sus salarios.

${ }^{21}$ J. H. van Mosseveld, ed., Keldermans. Een architectonisch netwerk in de Nederlanden, Staatsvitgevertij, s-Gravenhage, 1987.

${ }_{22}^{2}$ Neeffs, Alexander, Histoire de la peinture et la sculpture à Malines, vol.II, Gand, 1876, pp. 38-39.

${ }^{23}$ R.de Roo, «De Keldermansen naar de documentatie vit het Mechsele Stadsarchief», H.K.O.M. (Bulletin du Cercle Archéologique, Littèraire et Artistique de Malines, LVI, 1952, pp. 68-89.

${ }^{24}$ Neeffs, Alexander, Op. cit., p. 34.

${ }^{25}$ Ibid., p. 12.
} 
mo en madera que en piedra. Idéntica formación tuvo su abuelo, Andries I ( $†$ ca. 1500), a quien vemos trabajando indistintamente como entallador y maestro cantero, primero junto a su padre en la Puerta de Hauswyck (1444-45), y con su hijo Anthonis a partir de los años setenta en importantes obras de escultura, como los trascoros o jubé de la iglesia de Berg-op-Zoom y de Santa Catalina de Malinas ${ }^{26}$. Al menos dos de sus hermanos, Andries y Mathijs - tío y padre respectivamente de quien ahora nos ocupa- siguieron a su vez los pasos de su padre.

La actividad de Mathjis o Mathieu II Keldermans documentada († antes de X-1525) está más relacionado con obras de escultura que de arquitectura. Su primera obra es una estatua de San Romualdo para la «Puerta de Bruselas» en Malinas (1478-79) ${ }^{27}$. En 1487 se ausentó de la ciudad, pero a pesar de que Neeffs supuso que se encontraría en el extranjero ${ }^{28}$, lo cierto es que hoy conocemos su biografía casi año por año al menos hasta $1505^{29}$ sin que se haya documentado viaje alguno fuera de los Países Bajos. En los años ochenta trabajó una vez más como escultor en el portal de la Iglesia de Hulst y en el desaparecido jubé de Boubourg ${ }^{30}$. En los primeros noventa era maestro de las obras de la parroquial de San Pedro de Lovaina, también se le documenta proporcionando piedra para la Catedral de Amberes ${ }^{31}$ y esculpiendo algunas estatuas para el ayuntamiento de Middelburg ${ }^{32}$. A principios del siglo siguiente trabajaba en el Palacio de Margarita de Austria en Malinas, pero probablemente no como arquitecto sino como escultor ${ }^{33}$. Sus últimas obras documentadas son también de escultura: el trascoro de la Iglesia de Brecht (1502) y el Tabernáculo de la Abadía de Averbode (1504) ${ }^{34}$. Un último dato de particular interés es que era propietario de unas canteras de piedra, lo que explica las ocasiones en que se le documenta entregando materiales para distintos edificios ${ }^{35}$.

Al menos tres de los hijos de Matthjis siguieron sus pasos: Matthijs III (doc. 1503-17), quien se trasladó a Lovaina y trabajó indistintamente como escultor y arquitecto ${ }^{36}$ y los dos que emigraron al extranjero, Antonio y su más que probable compañero de aventuras, su hermano pequeño Michel.

Las conclusiones que podemos sacar de esta tediosa relación de nombres, datos y obras, son de interés para perfilar la personalidad artística de Antonio de Malinas. Suponiendo, como parece más que evidente, que se formó en el taller de su padre y que su aprendizaje no diferiría del de su hermano, Antonio de Malinas estaría familiarizado con obras de cantería lo mismo que con los oficios de entallador e imaginero, fundamentalmente en piedra. Si a esto añadimos que su llegada a Portugal debió de ocurrir hacia 1517 y que en 1523 ya tenía tres hijos, entonces, el maestro que emprendió viaje a la Península Ibérica debía de tener perfectamente terminada su formación.

La primera noticia que tenemos de Antonio Keldermans III lo sitúa ya fuera de los Países Bajos. El cinco de noviembre de 1518, sus hermanos Jan, Andries, Barbele y Matthijs firmaban en Malinas un poder a favor de Antonio y Michel ${ }^{37}$, que están en el extranjero, para po-

\footnotetext{
${ }^{26}$ Ibid., pp. 13-14; Neeffs, Alexander, Op. cit., pp. 20-29.

${ }^{27}$ Neeffs, Alexander, Op. cit., p. 34. Una biografía actualizada en: Keldermans. Een architectonisch..., pp. 18-19.

${ }^{28}$ Ibídem.

${ }^{29}$ Keldermans..., ibídem.

${ }^{30}$ Squilbeck, Jean, Op. cit., p. 109.

${ }^{31}$ Neeffs, Alexander, Op. cit., p. 35. Keldermans..., p. 18.

${ }^{32}$ Ibídem.

${ }^{33}$ Squilbeck, Op. cit.

${ }^{34}$ Ibídem.

${ }^{35}$ Neeffs, Alexander, Op. cit., p. 35.

${ }^{36}$ Neeffs, Alexander, Op. cit., pp.37-38. Squilbeck, Jean, Op. cit., pp. 132 y ss. Keldermans..., p.22.

${ }^{37} \mathrm{El}$ nombre de este segundo hermano es problemático y su clarificación de singular importancia para nuestro trabajo. Neeffs lo llama «Maarten», sin embargo una lectura correcta de este documento (único en el que aparece recogido su nombre) lo convierte en «Michel» (Miguel). Debo a la amabilidad y paciencia del archivero, el señor Henri Installé, la transcripción y traducción de todos los documentos manuscritos en flamenco de este archivo que se citarán de aquí en adelante.
}

AEA, LXXVII, 2004, 306, pp. 139 a 157 

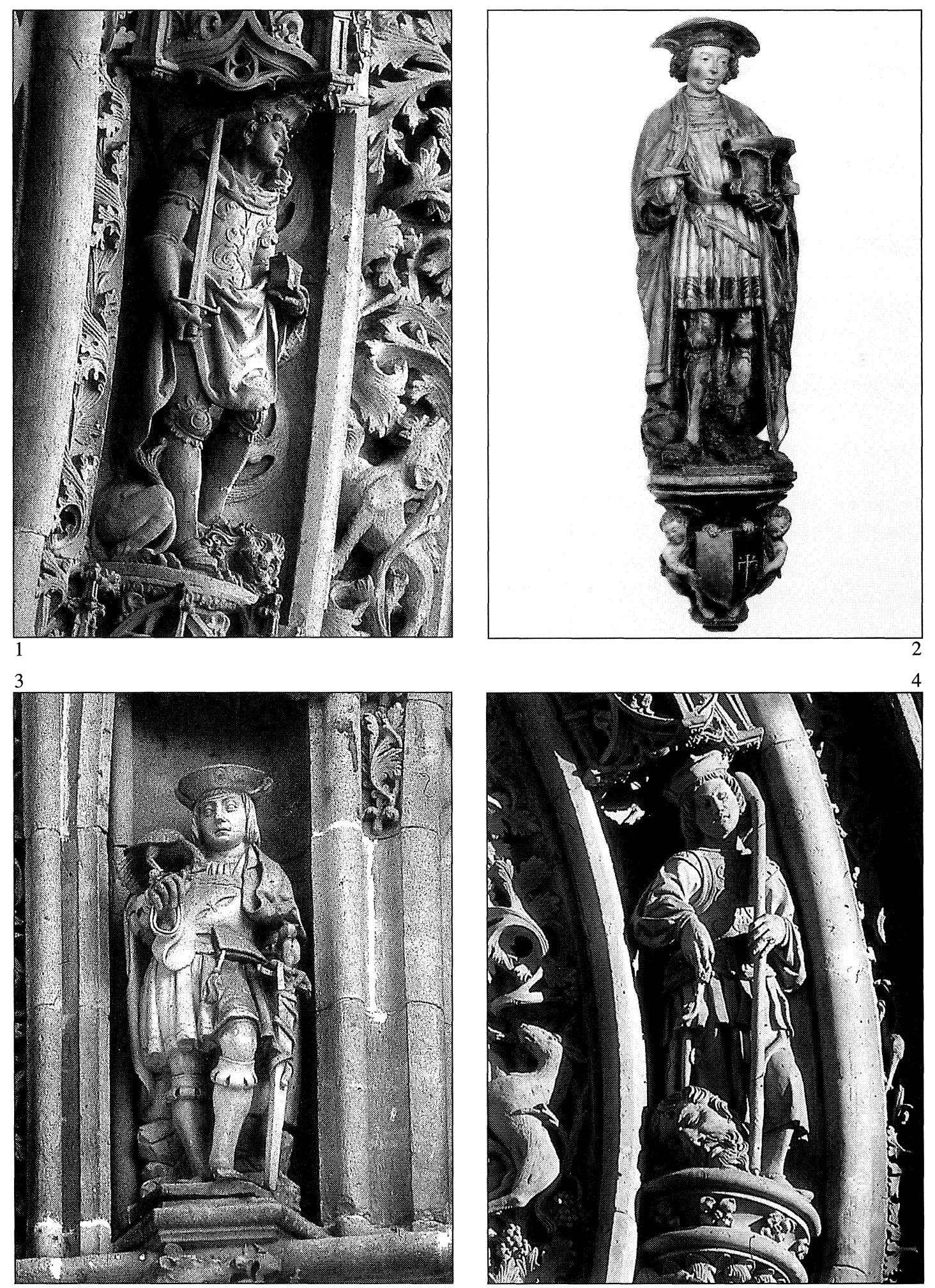

Fig. 1. San Adrián. Puerta del Obispo. ¿Antonio de Malinas?

Fig. 2. San Adrián, ca. 1500. Museo del Ayuntamiento de Malinas.

Fig. 3. San Julián Hospitalario. Puerta de San Clemente. ¿Antonio de Malinas?

Fig. 3 bis. David. Puerta central. ¿Antonio de Malinas?

AEA, LXXVII, 2004, 306, pp. 139 a 157 
der cobrar los beneficios de un dinero entregado junto con su padre al hospicio de la Santa Trinidad de Mechelen ${ }^{38}$. La presencia de su hermano Michel junto con Antonio es de singular importancia, no sólo porque señala la existencia de un pequeño taller familiar trabajando al mismo tiempo, sino por la posibilidad de identificar a este segundo maestro con alguno de los escultores de Malinas que en años siguientes se documentan en Castilla ${ }^{39}$.

El 1 de febrero de 1520 Antonio se encontraba todavía fuera de su país ${ }^{40}$, y por fin al año siguiente se especifica que su lugar de residencia era Portugal ${ }^{41}$. Los siguientes datos que conocemos de su periplo viajero le sitúan ya en Salamanca, entre abril de 1523 y el 31 de julio del mismo año. Como hemos dicho, en esa última fecha nuestro escultor desaparece de Salamanca, para no volver a surgir hasta mayo del año siguiente.

Ahora bien, debemos preguntarnos por qué abandonó Antonio Keldermans Salamanca cuando todavía no habían terminado sus obligaciones con la fábrica salmantina. La respuesta se encuentra en el primero de los dos testamentos que se han podido localizar. El documento - sin rubricar- del Archivo Municipal de Malinas lleva por fecha el 12 de agosto de 1523, dos semanas después del último libramiento recogido en los libros catedralicios ${ }^{42}$. Ese día Antonio de Malinas compareció ante notario y en el breve testamento, apenas una veintena de apresuradas líneas, afirma que encontrándose en Portugal sus hijos Mattheus, Barbele e Isabel, todos ellos hijos naturales de Maria Alvers, y teniendo la intención de reunirse con ellos, pero no la seguridad de llegar vivo a Portugal, como tampoco de poder volver a Malinas, disponía mortis cau$s a$ a favor de sus tres hijos a partes iguales de todos sus bienes muebles e inmuebles (los cuales no se especifican) así como del usufructo de lo recibido en la herencia de su padre ${ }^{43}$.

La referencia a Portugal es consistente con la información disponible acerca de las vías de penetración de los entalladores e imagineros a Salamanca en estas fechas. Son varios los artistas del norte que entraron desde el país vecino ${ }^{44}$. El más notable es el del pintor y dorador Juan de Yprès quien fue llamado para hacerse cargo del dorado del nuevo retablo del Estudio. Según se recoge en el claustro del 7 de agosto de 1503 las autoridades universitarias «... dijeron a Juan Dipre dorador e pintor que dónde estaba para si la universidad le enbiare a llamar para el retablo; el qual dijo que en Coimbra en Portugal» ${ }^{45}$, donde efectivamente se

\footnotetext{
${ }^{38}$ Stadsarchief Mechelen, Procuratoria, 1, fo 217; la signatura en R.de Roo, Op. cit., p.81.

${ }^{39}$ Un «Miguel de Malinas entallador» se documenta en Tordesillas en 1547, 1565, 1572 y 1574: García Chico, E., Documentos para el estudio del arte en Castilla, Valladolid, 1941, pp. 64-67.

${ }^{40}$ Neeffs, Alexander, Op. cit., p. 38.

${ }^{41}$ R.de Roo, Op. cit., p. 81. Por lo que sabemos, ningún Antonio de Malinas ha sido identificado en Portugal hasta la fecha, si bien podría tratarse de un cierto «Amtoneo Fermego» que aparece trabajando en el portal sur de la iglesia de los Jerónimos de Belem en 1517: Correia, Vergilio, As obras de Santa Maria de Belem de 1514 a 1519, Lisboa, 1922, pp. 17 y 19. Paul Vitry lo intrepreta como «framengo»: «Essai sur l'Ouvre des sculpteurs françaises...», pp. 5-6.

${ }^{42}$ Por supuesto, no resulta imprescindible que se encontrara todavía en Salamanca en esa fecha, pudiendo haberse depositado el pago en manos de un tercero que actuara en su nombre. En cualquier caso, aunque el plazo es breve, es suficiente para trasladarse a su ciudad de origen, dada la proximidad de Malinas del puerto de Amberes. Lo lógico hubiera sido dirigirse al puerto de Bilbao, donde se concentra el mayor número de naves que hacían este recorrido, unas cuatrocientas a fines del siglo xvi: Carande, Ramón, Carlos V y sus banqueros, I, Barcelona, 1987, p. 367; Guiard y Larrauri, Teófilo, Historia del Consulado de Bilbao y del Comercio de la Villa. Vol. I, Bilbao, 1913, pp. 119-124 y 151. En cuanto a la distancia que se podía recorrer por tierra, valga el ejemplo de Jerónimo Münzer, que cubre 14 leguas en una jornada, unos ochenta kilómetros, con lo que, de haber elegido ese puerto, habría tardado alrededor de una semana en llegar a la costa (Jerónimo Münzer, Viaje por España y Portugal 1494-1495, Madrid, 1991, pp. XXI-XXIV). El tiempo que empleaba el trayecto marítimo debía de ser muy variable. Un ejemplo puede ser la flota de Juana la Loca en su viaje a Flandes de 1496 Saliendo de Laredo emplearon, en las mismas fechas de agosto, algo menos de dos días y medio en llegar al Canal de La Mancha.

${ }^{43}$ Stadsarhief Mechelen, Schepenbrieven, 146, $\mathrm{f}^{\mathrm{o}} 78 \mathrm{v}^{\circ}$. R.de Roo, Op. cit., p. 81; Neeffs, Op. cit., p. 38.

${ }^{44}$ Numerosos ejemplos de entalladores procedentes de Castilla que trabajan indistintamente a ambos lados de la frontera, como los más sobresalientes de Juan Alemán o Juan de Colonia, en: Correia, Vergilio, «A Escultura em Portugal no primeiro terço do século xvı», Arte e Arqueología, Vol. I, nº 1, 1929, pp. 5-24. 329.

${ }^{45} \mathrm{AUSa}, 4, \mathrm{f}^{\circ} 24 \mathrm{v}^{\circ}$. Gómez-Moreno, Manuel, «La Capilla de la Universidad de Salamanca», B.S.C.E., 1914, pp. 321-
}

$A E A$, LXXVII, 2004, 306, pp. 139 a 157 

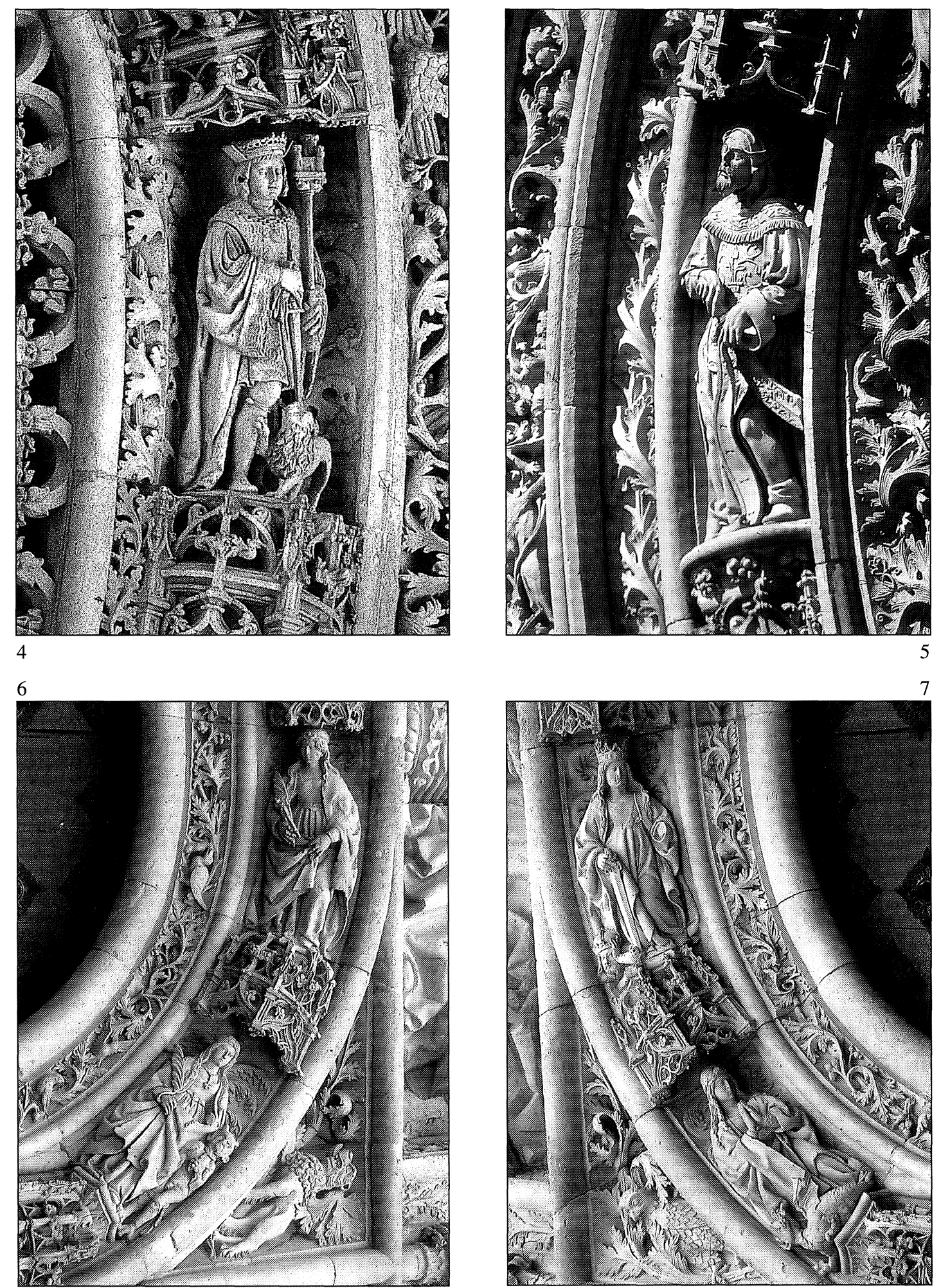

Fig. 4. Rey de Armas. Puerta de San Clemente. ¿Antonio de Malinas?

Fig. 5. Profeta desenvainando una espada. Puerta central. ¿Antonio de Malinas?

Fig. 6. Santa Apolonia y Santa Margarita. Puerta central. ¿Antonio de Malinas?

Fig. 7. Santa Catalina y Santa Marta. Puerta central. ¿Antonio de Malinas? 
encontraba, ocupándose nada menos que del retablo de su Catedral junto con el imaginero, también extranjero como no podía ser de otra manera, Oliverio de Gante ${ }^{46}$. Su condición de ciudad universitaria hacía de Salamanca un lugar de intercambio artístico y cultural de primer orden, de tal modo que, debido además a su proximidad geográfica, era un destino privilegiado para los estudiantes portugueses ${ }^{47}$.

Por otro lado, el término geográfico «Portugal» puede ser engañoso. Es posible que al mismo tiempo que trabajaba en Salamanca Antonio mantuviera su residencia en el país vecino, pero también cabe la posibilidad de que se refiriera vagamente a aquel país, en referencia a la Península Ibérica ${ }^{48}$. De hecho, sabemos documentalmente que, años después, Antonio Keldermans se encontraba en España, donde le esperaba la muerte fatal que cautamente preparaba en su testamento. También es probable que el de Malinas, habiéndose asegurado el trabajo en la Península Ibérica, y con tres hijos a sus espaldas (alguno de los cuales podría haber nacido ya en tierras extranjeras como lo hizo el cuarto y último del que tenemos constancia) decidiera regularizar la situación de su herencia.

No sabemos en qué fecha concretamente regresó Antonio Keldermans a Salamanca, pero al menos el dos de mayo de 1524 estaba de regreso en la ciudad castellana, la última vez que aparece en la ciudad del Tormes. Su desaparición plantea una incógnita por el momento insoluble. No deja de ser extraño que después de volver a Malinas para testar, lo que parece indicar que un trabajo de cierta envergadura le aguardaba en el extranjero, cuando vuelve a Salamanca tan sólo se le documente en una ocasión, y para cobrar la ridícula cantidad de 850 maravedís. Para solucionar este enigma caben dos hipótesis. O bien Antonio de Malinas regresó mucho antes de mayo de 1524 (es decir poco después de agosto del año anterior en que testa) y por lo tanto estuvo trabajando en la Catedral entre septiembre de 1523 y mayo del año siguiente aunque no se registren pagos a su nombre; o bien no llegó de vuelta a Salamanca hasta mucho más tarde y entonces hay que prolongar su estancia - que tampoco está documentada - durante la segunda mitad de 1524. La posibilidad más realista de las dos parece la primera.

Lo único que podemos asegurar con toda certeza es que Antonio había dejado realmente Malinas, y que había conseguido reunirse con su familia, como confirma que en las Adhéritances de Malines, figure como ausente el 14 de octubre de $1525^{49}$. A partir de este momento,

${ }^{46}$ Vitry, Paul, Op.cit., p. 5. Dos Santos, Reynaldo, «La Sculpture flamande au Portugal à l'epoque Manuéline», Miscellanea Leo van Puyvelde, Bruselas, 1949, pp. 291-296. Dos Santos, R., A Escultura em Portugal, Lisboa, 1950, vol.II, p.18. Dacos, Nicole, «Os artistas flamengos e a sua influência em Portugal (sécs.XV-XVI)», Flandres e Portugal, Amberes, 1991, pp.143-175.

${ }^{47}$ Marqués, Armando de Jesús, Portugal e a Universidade de Salamanca. Participação dos escolares lusos no governo do Estudo (1503-1512), Salamanca, 1980. Se recogen en este trabajo los nombres de treinta portugueses en ese corto periodo desde estudiantes hasta el catedrático Aires Barbosa. Un segundo caso de artista nórdico que trabajara en Portugal antes de llegar a Salamanca es el de un entallador poco conocido, Francisco de Lorena, de quien sabemos que en 1549 contrató como ensamblador junto a los entalladores Hans de Sevilla y Sebastián de Toledo el retablo del convento de San Leonardo en Alba de Tormes: Pinilla González, Jaime, El arte de los monasterios y conventos despoblados de la provincia de Salamanca, Salamanca, 1978, pp. 187-188. Francisco de Lorena se relaciona a partir de 1550 con la talla de unas sillas para el monasterio de Santa Clara de Salamanca, trabajo que dejó inacabado habiendo fallecido ya el 23-X-1556: Barbero García y Miguel Diego, Op. cit., p. 117. Es más que probable que sea el mismo que un «Francisco Loreto, francez, marceneiro» que en 1532 contrataba las cajas de los órganos del monasterio de Santa Cruz de Coimbra: Quintino García, Prudencio, João de Ruão MD...MDLXXX. Documentos para a biographia de um artista, Coimbra, $1913, \mathrm{p} .249$. Dos Santos, Prudencio, Op.cit., p. 296; y que un año antes trabajaba en la sillería de la Catedral de Coimbra: Baptista Pereira, Fernando Antonio, «El Arte en Portugal en el tiempo del Tratado de Tordesillas, 1470-1530» en El arte en la época del Tratado de Tordesillas, Valladolid, 1994, p. 50.

${ }^{48}$ La generalidad con la que en la España de los siglos xv y xvi se utiliza el término «Flandes» para referirse a los Países Bajos, se acentúa en sentido contrario. Su imagen de los reinos de la Península sería si cabe más indeterminada. Cfr. Vosters, Simon A., Los Países Bajos en la literatura española. I. La Edad Media, Valencia, 1978, p. 388.

${ }^{49}$ Neefs, Alexander, Op. cit., p.38.

$A E A$, LXXVII, 2004, 306, pp. 139 a 157 

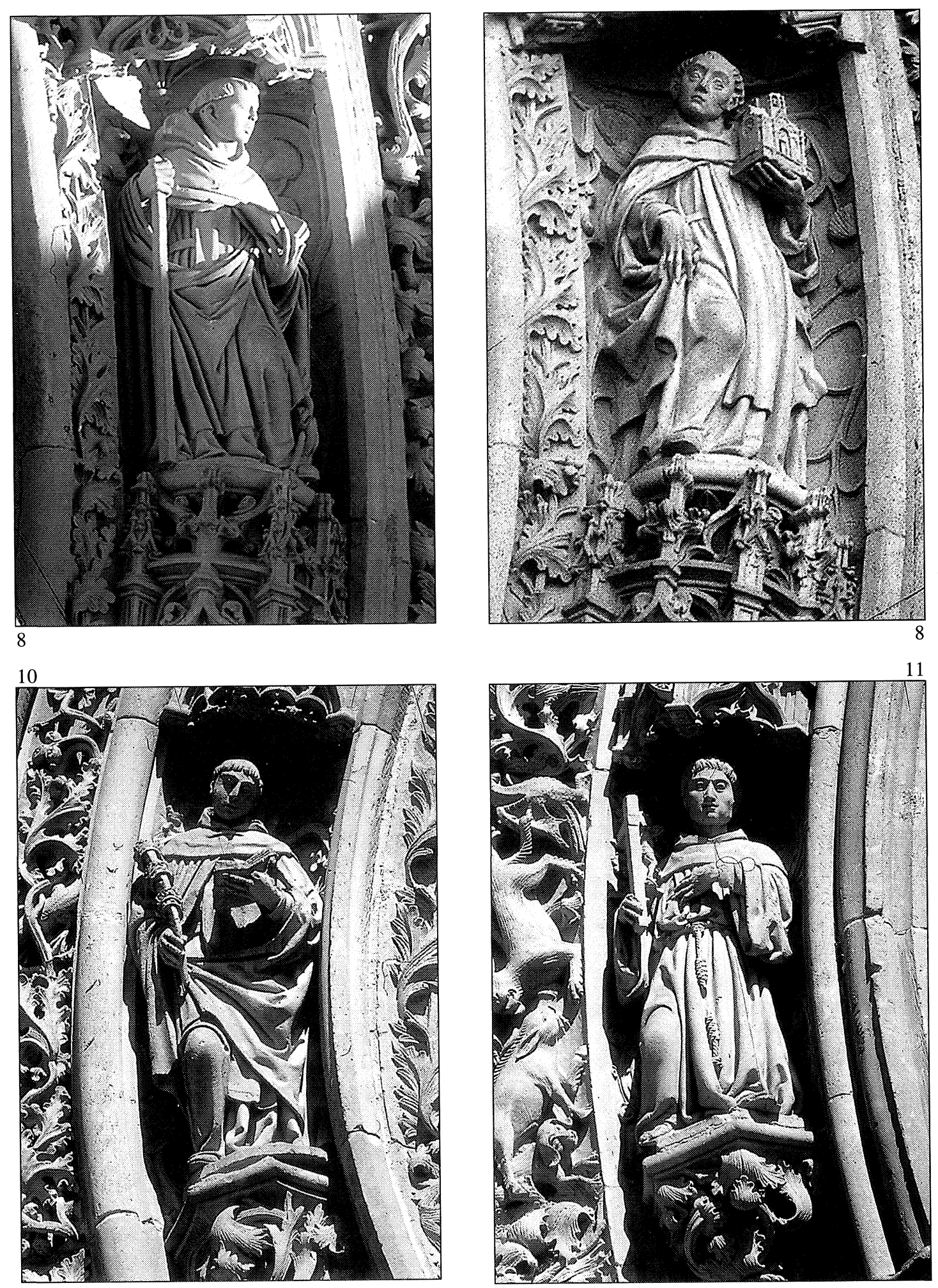

Fig. 8. Santo Domingo de Guzmán. Puerta de San Clemente. ¿Antonio de Malinas? Fig. 9. Santo Tomás de Aquino. Puerta del Obispo. ¿Antonio de Malinas?

Fig. 10. San Pedro Mártir. Puerta central. ¿Antonio de Malinas?

Fig. 11. San Francisco de Asís. Puerta central. ¿Antonio de Malinas? 
su pista se pierde en la ciudad que probablemente abandonaría poco después, también por razones que desconocemos, siendo sustituido de forma inmediata por dos nuevos entalladores. Uno de ellos lo hará brevemente; se trata de un cierto Domingo de Vidaña, quien surge en 1524, cobrando un total de 1.496 maravedís ${ }^{50}$. El segundo, mucho más importante, es el Maestro Gil de Ronça, registrado en los Libros de Cuentas en un periodo muy preciso de un año: desde el 26 de agosto de 1524 hasta septiembre de 1525, recibiendo como ya hemos dicho, el más cuantioso de los libramientos ${ }^{51}$.

En cualquier caso, nada podemos añadir a su biografía hasta cinco años más tarde, cuando firmó el último de los dos testamentos conocidos. Se trata, que sepamos, de la segunda de las tres veces que Antonio Keldermans volvió a su ciudad natal durante los años que trabajó en el extranjero. Este testamento es algo más prolijo que el anterior ${ }^{52}$. En él «Antonio van Mansdale alias Keldermans» declaró que «en forma de limosna y por la voluntad de Dios deja a sus hijos naturales Mattheus, Antoon, Elisabeth y Margareta que tiene de Maria Alvers todos los bienes muebles e inmuebles que posee así como sus deudas presentes y futuras; asimismo que la dicha Maria Alvers sea la tutora de sus hijos hasta que lleguen a edad adulta, tras lo cual le serán entregados a la dicha Marie Alvers 100 florines de renta y caso de que alguno de sus hijos muriera antes de llegar a adulto que su parte sea dividida entre los demás hermanos» ${ }^{53}$.

Son pocas las conclusiones que podemos extraer del citado documento, excepto la existencia de un nuevo hijo de nombre Antonio, que habría nacido entre 1523 y 1528. Su nacimiento pudo haber motivado de nuevo su presencia en Malinas. Si fue así, entonces la conclusión lógica es que siempre consideró su estancia en el extranjero como provisional, lo que le obligaba a arreglar regularmente su situación en Malinas, donde algún día esperaría volver a establecerse con su familia. Nada se dice sobre el lugar donde se encontraban su mujer e hijos, pero tampoco tenemos ningún dato que nos lleve a pensar que habían regresado a Brabante.

En algún momento después de 1528 , pero antes de 1531 año en el que sabemos que emprendió el regreso por vía marítima de su tercer y último viaje a la Península Ibérica, Antonio probó fortuna en Flandes, pero los resultados no fueron siempre satisfactorios. Alrededor del año 1528 está documentado colaborando con su primo, el acreditado Rombout Keldermans en la iglesia de Santa Catalina de Hoogstraten ${ }^{54}$ y de nuevo con este mismo en el castillo de Hoogstraten con la humilde categoría de un «metselaar», un albañil ${ }^{55}$. Terminado su trabajo sabemos que construyó una casa de recreo para Elisabeth van Culembourg extramuros de la ciudad de Culemborg ${ }^{56}$. Quizá por motivos de falta de trabajo, o de las condiciones en que se vio obligado a ganarse la vida en alguna ocasión, en cualquier caso, lo cierto es que Antonio volvió a probar fortuna por tercera y última vez en España.

\footnotetext{
${ }^{50}$ No sabemos prácticamente nada de este imaginero y entallador. La primera noticia que tenemos le sitúa ya en Salamanca, el 25 de mayo de 1524 (ACSa, Libro de Cuentas de Fábrica, f. 285). Como «imaginario» tan sólo aparece dos veces más, el 18 de julio, cobrando quince reales (Ibidem), y el 9 de agosto, 986 maravedís (Ibid., f. 235). Luego desaparece, para resurgir en 1526, esta vez ya como entallador, individualmente con Diego Delabe o Delahe, uno de los dos entalladores franceses que surgen en este momento y que se ocupaban de hacer «florones» para las claves de las capillas. Más adelante Delahe se ocupará de la sillería, por lo que debía estar especializado en la talla en madera. Suponemos que cuando Domingo de Vidaña aparece como «entallador» está trabajando en madera al igual que el anterior, y no en imaginería de piedra como lo había hecho dos años antes. En 1526 Domingo de Vidaña era vecino de Salamanca. Así lo afirma cuando firma como imaginero dando fianzas a Juan Sánchez de Alvarado el 11 de Mayo, diciendo asímismo que es yerno de Benito Sánchez Carpintero, Cfr. Chueca Goitia, Op. cit., p. 94.

${ }^{51}$ Los pagos a Gil de Ronza pagos alternan con los de su hijo Diego de Ronça — «Maestro Diego»- que recibe en septiembre de $1525,7.100$ maravedís.

${ }^{52}$ Stadsarchief Mechelen, Schepenbrieven, 151, fo $142 \mathrm{v}^{\circ}$. R.de Roo, Op. cit.

${ }^{53}$ Se trata una vez más de mi traducción española de la transcripción y traducción francesas del señor archivero, Henri Installé.

${ }^{54}$ Keldermans. Een architectonisch netwerk..., p. 82

${ }^{55}$ Idem., p. 162.

${ }^{56}$ Ibidem. No hemos podido precisar las fechas exactas ni el alcance de su intervención en esta obra.
} 

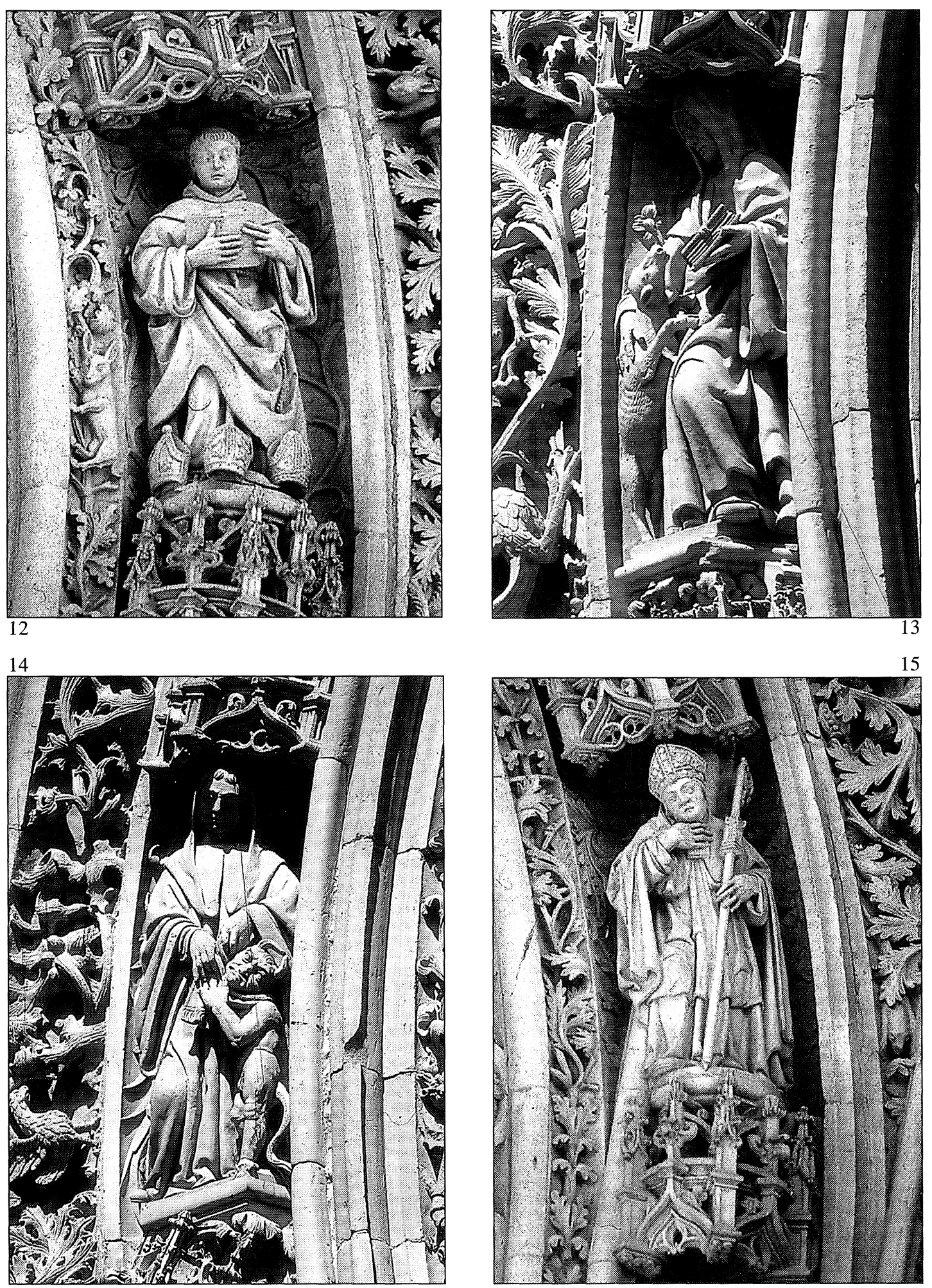

Fig. 12. San Bernardino de Siena. Puerta de San Clemente. ¿Antonio de Malinas? Fig. 13. San Gil. Puerta central. ¿Antonio de Malinas?

Fig. 14. San Juan de Sahagún. Puerta central. ¿Antonio de Malinas?

Fig. 15. San Blas. Puerta de San Clemente. ¿Antonio de Malinas? 
Le quedaban sin embargo pocos años de vida. El 20 de Noviembre de 1531, al menos así constaba en un acta del Registro de la Cámara Popular que pudo ver Neefs ${ }^{57}$, Antonio Keldermans ya había fallecido. Las circunstancias de su muerte añaden a la ya de por sí ajetreada historia de su vida un final dramático. Según este mismo historiador el genealogista Valckenisse había escrito que nuestro personaje murió en el mar frente a las costas de España ${ }^{58}$. Aunque no nos informa exactamente de donde obtuvo esa información, creemos haber encontrado su fuente en un manuscrito de este autor que se conserva en el Archivo Municipal de Amberes. En un volumen dedicado a la nobleza de aquella ciudad André-Eugène Vlanckenisse (1630-1701) incluye un árbol genealógico de la familia de los van Mansdale ${ }^{59}$ a partir de la quinta generación de artistas de esta familia, es decir, precisamente desde la que corresponde al viajero salmantino. En el lugar correspondiente puede leerse: Anton de Mansdale retournant d'Espagne ed moura sur la mer laisse un fils Mathieu.

Como escribiera Neeffs, no hay ninguna razón para dudar de la veracidad de esta noticia. Las precauciones de Antonio Keldermans acabaron confirmándose y el tercero de sus viajes terminó en una tragedia que todos los datos apuntan a imaginar en la forma de un naufragio. $\mathrm{Al}$ contrario que los documentos anteriores en este sí que se especifica España como el lugar en el que Antonio de Malinas había estado trabajando. Su muerte acaecería entre 1528 y 1531 lo que nos deja un lustro de actividad absolutamente desconocida.

Un último detalle de su biografía merece nuestra atención. Me refiero a los restantes miembros de la familia Keldermans que emigraron buscando oportunidades en el sur de Europa. En primer lugar tenemos a su hermano pequeño Michel quien, según consta del poder que firmaron sus hermanos en noviembre de 1518, estaba también en el extranjero, no necesariamente en el mismo lugar, pero sí muy probablemente, lo que le convierte en un más que probable colaborador del taller de Antonio en la Catedral de Salamanca ${ }^{60}$. El siguiente es un hijo del propio Antonio, Mattheus Keldermans. Sabemos por el testamento de 1523 que se encontraba en Portugal en esa fecha y también que en 1556 se presentó ante el gremio de maestros poco antes de dejar Malinas para dirigirse al extranjero ${ }^{61}$. De Roo supone que fue a Castilla siguiendo los pasos de su padre ${ }^{62}$, pero nada hemos podido averiguar sobre su destino.

\section{Formación artística}

La relativamente abundante bibliografía dedicada e a la actividad de la familia Keldermans como escultores y arquitectos, así como la referida a la formación artesanal en los gremios de la ciudad, nos permite clarificar la formación de nuestro imaginero a su llegada a España. Desde su mismo origen los maestros de la familia se habían dedicado indistintamente a ambas actividades, la cantería y la escultura, alternando también la arquitectura con obras de tipo ingenieril, como fortalezas. Esta actividad doble coincide con la especialización profesional establecida en los gremios de su ciudad de procedencia. La organización del trabajo en los talleres de Malinas parece haber sido semejante al del resto de los países del norte de Europa ${ }^{63}$.

\footnotetext{
${ }^{57}$ Neeffs, Alexander, Op. cit., p. 39.

${ }^{58}$ Ibídem.

${ }^{59}$ De Vlanckenisse, André-Eugène, Noblesse et autres familles patriciennes et considerables de la Ville d'Anvers et Marquisat du St Empire et autres» (1668), Stadsarchief Antwerpen, PK 167, (3 vols), vol. II, $\mathrm{f}^{\circ} 407$.

${ }^{60}$ Véase notas 36 y 38.

${ }^{61}$ Stadsarchief Mechelen, Ambachten Metsers, III, 1, fo 1-2. Citado por: de Roo, Op. cit., p. 82.

${ }^{62}$ Ibídem.

${ }^{63}$ Sobre los orígenes de la separación entre maestros canteros, entalladores e imagineros, véase un estado de la cuestión en el que se interpreta el surgimiento de este útltimo oficio en relación con la importancia creciente de la escultura en la arquitectura gótica del siglo xv en: Baudoin, Jacques, La sculpture flamboyante. Les grandes imagiers d'Occident, París,
}

AEA, LXXVII, 2004, 306, pp. 139 a 157 
A mediados del siglo xv, los maestros que trabajaban en piedra se independizaron de la «Gilde» de San Lucas ${ }^{64}$. Entonces el gremio de canteros se agrupó bajo el nombre de «Cuatro Santos Coronados». Dentro de éste se ordenaron los cuatro oficios que estaban vinculados a la construcción: los canteros, bajo la advocación de San Claudio; vidrieros (San Castor); entalladores de piedra (San Nicóstrato) y escultores o «Kleynsteker» (San Sinforiano) ${ }^{65}$. Más adelante, los pintores y los escultores volverían a agruparse en un gremio de San Lucas, pero esto no ocurrió hasta después de $1541^{66}$. En el siglo XV esta organización respondía a la demanda de las grandes construcciones de cantería, y su estructura debió de venir motivada por el creciente papel de la imaginería en la decoración arquitectónica ${ }^{67}$.

Aunque supeditados originalmente a la colaboración con los canteros, el desarrollo de la imagen devocional a fines del siglo $\mathrm{xV}$ tuvo una influencia muy particular en la pequeña ciudad de Malinas. Una parte de los escultores de esta ciudad se especializaron en las conocidas «poupées» o muñecas de madera. Sus autores, también llamados «Kleynstekers» (escultores de pequeñas figuras) las trabajaban fundamentalmente en madera y más adelante también en alabastro (Alabasterwerckes) ${ }^{68}$. Un inventario aún no completo para el periodo que va entre 1470 y 1525 ha catalogado alrededor de 270 «poupées» repartidas por toda Europa. Su autora, Willy Godenne, no llegó a abarcar las existentes en España y Portugal, pese a suponerlas numerosas ${ }^{69}$. El caso de Portugal ha sido subsanado posteriormente. Sólo en ese país se han podido catalogar 76 esculturas ${ }^{70}$. Su abundancia en el país luso está claramente en relación con las privilegiadas relaciones comerciales que mantenía con Flandes en el siglo xv, un intercambio basado en la venta de especias y la compra de objetos metalúrgicos, tejidos, armas, cereales y otros alimentos.

Las pequeñas esculturas en madera de Malinas constituyen un producto del mercado artístico en el que no tenemos constancia de que se moviera ninguno de los Keldermans. De hecho, es importante distinguir entre estas pequeñas esculturas devocionales en madera destinadas al consumo y devoción privadas y la tradición de imaginería en piedra a la que pertenece Antonio de Malinas. Pese a todo, su extensa distribución y demanda en toda Europa tiene el valor del contexto. Primero, porque la iconografía que repite Antonio en la fachada de la Catedral de Salamanca tiene puntos importantes de semejanza con aquéllas, no sólo por su tamaño, sino por su iconografía. Los tipos de las «poupées» más comunes que fueron exportadas por ejemplo a Portugal fueron los de santas y mártires (Bárbara, Catalina, Margarita, Úrsula,

1983, pp. 53-65. Con análogas conclusiones pero adelantando las fechas hasta finales del siglo xIII: Goldstream, Nicola, Les artisans du Moyen Age. Les maçons et sculpteurs, Brepols, 1992, pp .62-69.

${ }^{64}$ Neeffs, Alexander, Op. cit., vol. I, pp. 3-9.

${ }^{65}$ Neefffs, A., Ibídem. Destrée, J., Étude sur la sculpture brabançonne au Moyen Áge, Bruselas, 1894, pp. 127-132. Bosschère, Jean de, La sculpture Anversoise aux XV et XVI siècles, Bruselas, 1909, p. 81. Crab, Jan, «De Beeldsnijders en hun ambacht», Acta Lovaniensis. Artes atque historiae reservans documenta, 1972, pp. 69-94.

${ }^{66}$ Ibídem.

${ }^{67}$ Sabemos poco del funcionamiento interno del gremio, pero sí se conserva un «Libro de Aprendices» de pintores y escultores, que recoge los nombres de los inscritos, parcialmente desde fines del siglo, y de una manera más regular desde mediados del siglo xvi. Véase, Hyacinthe Coninckx, Le livre des apprentis de la Corporation des Peintres \& Sculpteurs à Malines, Malines, 1903.

${ }^{68}$ G.van Doorslaer, L'Enseignement de l'Exposition d'Art Ancien de Malines en 1911, Anvers, 1912, pp. 66-67. Jansen, Jaak, "Mechelse rondsculpturen in hout tijdens de Renaissance: de studie van twee modellen», en Mechels houtnijwerk in de eeuw van Keizer Karel, Mechelen, 2000, pp. 11-45, especialmente, pp. 14-18. Una introducción general en: Gert von der Osten y Horst Vey, Painting and sculpture in Germany and the Netherlands, 1500-1600, London, 1969 , p. 59.

${ }^{69}$ Godenne, Willy, «Préliminaires à l'inventaire général des statuettes d'origine malinoise présumées des XV et XVI siècles», Bulletin du Cercle Archéologique, Littéraire et Artistique de Malines, LXI, 1957, pp.47-127; LXII, 1958, pp.5180; LXIII, 1959, pp.30-54; LXIV, 1960, pp.108-129; LXVI, 1962, pp.67-156; LXXIII, 1969, pp.43-87; LXXVI, 1972, pp.1-80; LXXVII, 1973, pp.87-155; LXVII, 1974, pp.93-104 y LXXX, 1976, pp.71-105.

${ }^{70}$ Ferrão de Tavares e Távora, Fernando, Imagens de Malines, catálogo de la exposición del Museo Nacional de Arte Antiga, Lisboa, 1976. No hemos podido consultar el catálogo de este mismo autor (Museu, $2^{\mathrm{a}}$ serie, $\left.\mathrm{n}^{\circ} 16-17,1975\right)$ resumido en la publicación anteriormente citada. 
Inés, Cecilia, Dorotea, etc); la Virgen con el Niño, la Santa Ana Triple y fundamentalmente los santos Roque, Miguel Arcángel, Agustín y Cristóbal ${ }^{71}$. Éste es aproximadamente el contenido del encargo del salmantino.

En cuanto a las razones que pudieron motivar su emigración a España, son varias. En primer lugar, el éxito de este comercio, y en general la popularidad de los artistas de la pequeña ciudad del principado de Lieja, condujo a lo que parece una auténtica superpoblación de maestros ${ }^{72}$. La emigración de artistas de Malinas ha sido someramente estudiada. Hyacinthe Coninckx piensa que fue la conveniencia personal lo que lanzó a los primeros viajeros a buscar fortuna, y sólo en una segunda etapa jugaron las razones políticas ${ }^{73}$. La biografía de Antonio Keldermans, permite matizar el sentido de esta «conveniencia» en el contexto de una fuerte competencia artística. En cuanto a la elección de su destino pueden apuntarse dos razones. La primera reside en la búsqueda de un mercado en el que no dominara el sistema proteccionista de los gremios ${ }^{74}$. La segunda es la fortuna que una de las ramas de los Keldermans, la formada por su tío Antoine $(\dagger 1512)$ y sus primos Antoine II ( $†$ 1515) y el célebre Rombaut $(\dagger 1531)$, habían cosechado en la corte de Margarita de Austria y del emperador Carlos: Antonio Keldermans I «el viejo» († 1512), mantuvo estrechas relaciones con la Corte, recibió el título de «maître ouvrier de Monsegnieur le Roy», a la sazón el jovencísimo Carlos de Habsburgo ${ }^{75}$ y en 1507 comenzó el Palacio de Margarita de Austria en Malinas ${ }^{76}$. Con él queda inaugurada la lista de miembros de su familia que trabajaron para el Emperador. Anthonis II «el joven» († 1515), su primer y malogrado hijo le sucedió en todos sus encargos y llevó el título de «Maestro Mayor de las obras de la Corte de Margarita de Austria» ${ }^{77}$. El trío se cierra con Rombout II Keldermans ( $†$ 1531) quien ostentó el título de «Maître général des ouvres de l'Empereur ${ }^{78}$. No cabe duda que la vinculación de estos miembros de su familia a la Corte pudo haber decidido la elección de Antonio III a probar fortuna en la Península Ibérica, a donde se trasladó el joven Rey por primera vez en 1517, aunque desconozcamos si Antonio en algún momento intentó acercarse a la corte española.

\footnotetext{
${ }^{71}$ Ferrão de Tavares e Távora, Fernando, Op. cit., p. 32.

${ }^{72} \mathrm{El}$ «Libro de Aprendices» para la primera mitad del siglo xvi arroja un total de 315 aprendices y nada menos que 400 maestros Coninckx, Hyacinthe, Le livre des apprentis de la Corporation des Peintres \& Sculpteurs à Malines., p. 28. La presión demográfica de artistas es uno de los motivos sugeridos por J. Yarza para la emigración: «El Arte de los Países Bajos en la España de los Reyes Católicos», en Reyes y Mecenas. Los Reyes Católicos, Maximiliano I y los inicios de la Casa de Austria en España, Madrid, 1992, p. 145.

${ }^{73}$ Coninkx, Hyacinthe, Artistes malinois à l'etranger, Anvers, 1913, pp. 3-4. En el listado de este autor no se recoge ninguno de los escultores de los que es objeto este estudio.

${ }^{74}$ Un caso anecdótico del fuerte proteccionismo de los gremios en los Países Bajos del Norte es el de un cierto Jean van Dickele, escultor de Gante que en 1513 pasaba a la justicia por haber confeccionado «dos puertas de armario» sin tener el permiso correspondiente. Cfr. De Busscher, Edmond, Recherches sur les peintures et sculpteurs à Gand aux XVI ${ }^{e} x_{I I} e^{e}$ t XVIII siècles, Gand, 1866, p. 237.

${ }^{75}$ Henne, Alexander, Histoire du règne de Charles-Quint en Belgique, París, 1858, 10 vols., vol. V, 1859, p. 70. Saintenoy, Paul, Les arts et les artists à la Cour de Bruxelles, 3 Vols., T. V, Bruselas, 1932, p. 169. Squilbeck, Jean, «Notices sur les artistes van Mansdale dite Keldermans, B.R.A.L.A.M., LVII, 1952, p. 104.

${ }^{76}$ Saintenoy, Paul, Op.cit., vol. I, p. 170. Una introducción a la arquitectura en la corte de Margarita de Austria en: I.Vandeviviere y C.Perier-d'Ieteren, Belgique Renaissante. Architecture, art monumental, Bruselas, 1973, pp. 13 y ss. Véase además: Eichberger, Dagmar, Leben mit Kunst. Wirken durch Kunst. Sammelwesen und Hof Kunst unter Margerete von Osterreich, Regentin der Niederlande. Brepols, Turnhout; 2002, pp. 69, 435-436 y 438-439.

${ }^{77}$ Squilbeck, Jean, Op. cit., p. 114.

${ }^{78} \mathrm{Ibid}$., p. 71. Rombout es sin duda una de las figuras más interesantes del primer tercio del siglo xvi. Convertido en arquitecto oficial del Emperador al fallecer su padre y su hermano, recibe algunos de los encargos más importantes de su momento, como el Palacio del Gran Consejo de Malinas y posiblemente el de la fachada del Palacio de Margarita de Austria en la misma ciudad (lo que le convertiría en uno de los introductores del Renacimiento en Flandes). Se sabe asímismo que dio planos para la capilla de Carlos V en el palacio de Bruselas. A partir de 1517 se asocia con Dominique de Waghemakere, y juntos construirán el bellísimo ayuntamiento de la ciudad de Gante: Neeffs, Alexander, Op.cit., p. 51. Génard, P., «Notice sur les architectes Herman le Vieux et Dominique de Waghemakere, Bulletin des Commisions Royales d'Art et d'Archéologie, IX, 1870, pp. 462-464.
}

$A E A$, LXXVII, 2004, 306, pp. 139 a 157 


\section{Estilo y obra de Antonio de Malinas en la Catedral}

Resulta complejo distinguir el estilo de un escultor del quien no conocemos ninguna obra segura. En realidad todo lo que sabemos de su trabajo en la Catedral de Salamanca es que contrató cincuenta figuras «solas», es decir, figuras de bulto y no talladas en los sillares. La aparición a partir de 1524 de otros dos maestros imagineros en las cuentas dificulta la individualización de su obra y, dada su desaparición en estas fechas, es dificil saber hasta qué punto llevó a buen término la tarea que se le había encomendado.

Para aislar un grupo de esculturas, es necesario despejar primero dos incógnitas. La primera, y más importante, se refiere a cuáles eran las «cincuenta figuras» que podían haberle sido encomendadas. En el hastial del Perdón hay un total de sesenta y cuatro esculturas en la fachada exterior (diez en cada una de las laterales y cuarenta y cuatro en la central) ${ }^{79}$, además de los seis apóstoles de la portada interior que forman parte de un proyecto no terminado - quedando vacíos los encasamientos para los seis apóstoles restantes-.

El número de «cincuenta» es por tanto muy aproximado al de las imágenes necesarias para la decoración de la portada central. Lo lógico es pensar que el Cabildo estaría interesado en primer lugar en cubrir con esculturas la parte más visible de la fachada, es decir la portada principal, y que sólo más adelante empezaría a proyectarse el resto de la decoración. Nuestra hipótesis es que Antonio de Malinas trabajó en las esculturas de esta portada, las cuales no necesariamente habrían de ocupar el lugar para el que fueron pensadas, como demuestra el desorden iconográfico en que se encuentra buena parte del conjunto. Por este motivo, resulta imprescindible contar a su vez con un segundo grupo de gran calidad consistente en las veinte esculturas exentas que hoy ocupan las puertas laterales del Obispo ${ }^{80}$ y de San Clemente ${ }^{81}$, que por razones de calidad y antigüedad parecen pertenecer a la primera campaña escultórica ${ }^{82}$.

La segunda dificultad, en nuestra opinión insoluble en el presente estado documental, la plantea su deslindamiento con la figura de Gil de Ronza, el cual fue llamado «ex professo» a Zamora el 19 de julio de 1524 una vez había Antonio Keldermans abandonó el taller catedralicio ${ }^{83}$.

\footnotetext{
${ }^{79}$ En la portada central el primer grupo lo constituyen ocho figuras de Santas y Mártires: (de izquierda a derecha): Santa Marta, Santa Catalina, Santa Lucía, una Santa, sentada, sin atributo; Santa Bárbara, Santa Águeda, una Mártir, y finalmente Santa Margarita.

En el centro, el «Sacrificio de Isaac» forma parte de un grupo de catorce figuras de patriarcas ataviados con túnicas y llevando filacterias, en el que solo es posible identificar a David tocando el arpa y David con la cabeza de Goliat. En el intradós de los arcos hay las esculturas de ocho ángeles. Siete de ellos son ángeles músicos, y el restante forma parte de la escena del Sacrificio de Isaac. El espacio restante de las arquivoltas ha sido completado con esculturas de santos: tres de los Padres de la Iglesia (San Gregorio, San Agustín y San Ambrosio) además de Nicolás de Bari, junto a un cuarto Obispo que no podemos identificar. Siempre de izquierda a derecha las figuras representan en conjunto los siguientes santos: San Pedro Mártir, San Francisco de Asís, San Antonio de Padua, San Gil, Juan de Sahagún, San Nicolás de Bari, Obispo (¿San Agustín?), Obispo (¿San Ambrosio?), San Gregorio, Obispo leyendo un libro, Fray Juan Hortelano, San Antonio Abad, San Roque y para terminar, un Santo ermitaño.

${ }^{80}$ Son diez esculturas de Santos: San Martín de Tours, San Esteban, un Santo mutilado, San Sebastián, Santo confesor, San Adrián, Santo Tomás, San Vicente, San Lorenzo y San Benito.

${ }^{81}$ Diez esculturas de Santos ocupan estas arquivoltas: San Juan Hospitalario, San Martín de Tours, San Cosme, San Hipólito, Abdón, Senén, Santo Domingo, San Bernardino de Siena, San Blas y un Santo no identificado.

${ }^{82} \mathrm{~A}$ éstas hay que sumar un último grupo de doce esculturas quinientistas de muy inferior calidad que decoran la Puerta de Ramos o «del taller» en el norte de la Catedral.

${ }^{83}$ Con independencia de la posible - aunque en el estado actual de la documentación, también indeterminable - responsabilidad de este maestro en las esculturas de la fachada, hay buenas razones, tanto técnicas - la preferencia de este escultor por la madera como material-, como iconográficas - las relaciones con su obra documentada en la desaparecida capilla del deán Diego Vázquez de Cepeda en Zamora - para suponer que su trabajo estuvo centrado en la talla del centenar largo de esculturas de la Capilla de Diego Sánchez de Palenzuela construida simultáneamente al resto de la catedral. Para la reconstrucción de la primera, véase: Pereda, Felipe, «Escultura y teatro a comienzos del siglo xvi: la capilla del Deán Diego Vázquez de Cepeda», Anuario del Departamento de Historia y Teoría del Arte, VI, 1994, pp. 179-195. Para la biografía del escultor: Rivera de las Heras, José Angel, En torno al escultor Gil de Ronza, Zamora, 1998, con importantes aportaciones documentales.
} 


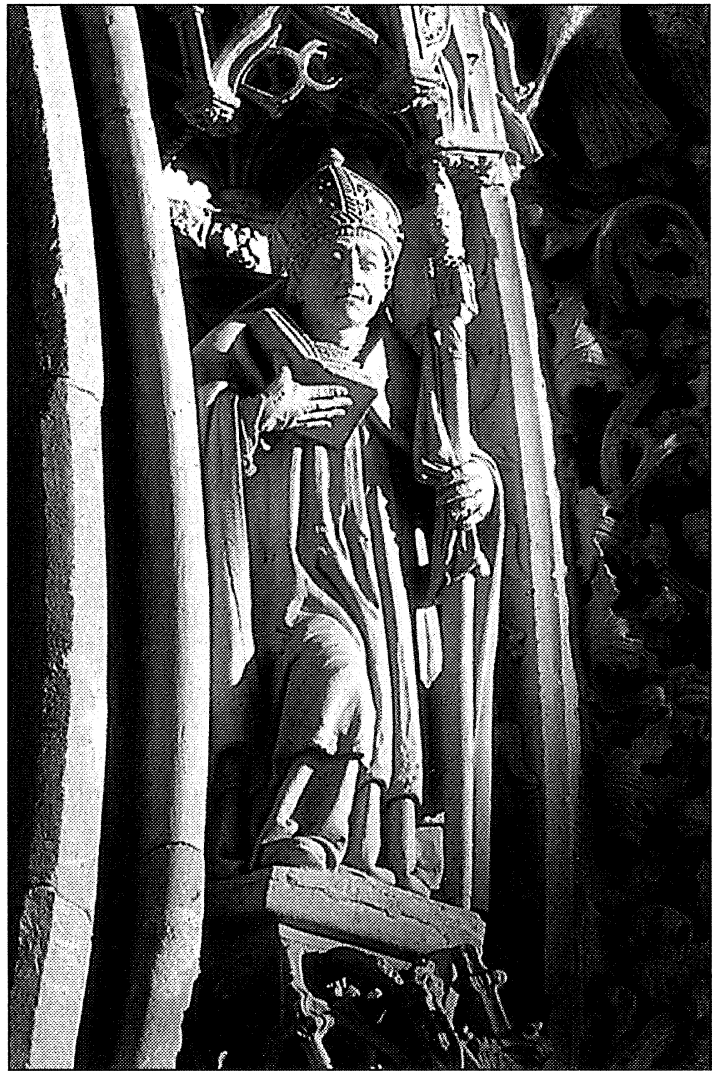

Fig. 16. Santo Obispo. Puerta central. ¿Antonio de Malinas?

Desgraciadamente, la destrucción generalizada de escultura monumental en los Países Bajos hace que sea muy difícil establecer paralelos de tipo formal que nos ayuden en nuestra discusión. Algunas de las imágenes de este grupo responden sin embargo a modelos iconográficos — «tipos» en el sentido amplio del término del primer Panofsky, esto es, no tanto imágenes en relación con leyendas orales o escritas, cuanto modelos figurativos acuñados por la devoción popular ${ }^{84}$ - que pueden relacionarse con la escultura exenta conservada en Malinas.

Éste es el caso de la figura de un santo cuya advocación e iconografía es muy poco frecuente en Castilla. La figura de san Adrián es una de las de mayor calidad de todo el conjunto. Un ejemplo comparativo procedente del Hospital de Nuestra Señora (hoy en el Museo del Antiguo Ayuntamiento de la ciudad) y datado en las primeras décadas del siglo XVI coincide tipológicamente con la escultura salmantina ${ }^{85}$. Las formas suaves y algo amaneradas características de los talleres de Malinas ${ }^{86}$ que forman parte de una tendencia general de la escultura de los Países Bajos en torno a 1500 - luego agudizada con el creciente contacto con el mundo italiano en torno a la corte de Margarita de Austria_- ${ }^{87}$ se constata en los dos casos, aunque el escultor de la catedral de Salamanca demuestre un sentido de la plasticidad y del volumen más moderno, producto sin duda del contacto con una nueva generación de escultores.

Tomando el estilo de esta escultura como modelo y guía, es factible establecer relaciones formales y de calidad con algunas de las esculturas de la portada central: en primer lugar con

\footnotetext{
${ }^{84}$ Panofsky, Erwin, «Imago Pietatis: ein Beitrag zur Typengeschichte des «Schmerzenmannes» und der «Maria Mediatrix», Fetschrift für Max J.Friedländer zum 60.Geburtstage, Leipzig, 1927, pp. 261-308.

${ }^{85}$ Véanse en Godenne, W., «Préliminaires à l'inventaire géneral des statuettes d'origine malinoise...», art. cit., LXIV, 1960, pp. 108-129. La datación no es segura. E.Neeffs, Tableaux, sculptures et objets d'art conservés dans les édifices religieux et civiles de Malines, Malinas, 1891, p. 265, las data ca. 1500. Más recientemente, se han retrasado a ca. 151025: F[rank] H[uygens], en Mechelse houtnijwerk in de eeuw van Keizer Karel, Mechelen, 2000, catálogo n¹2-13, pp. 132134.

${ }^{86}$ Los estudios locales individualizan el estilo de esta escuela señalando que la situación geográfica de Malinas la coloca entre los polos de atracción de Bruselas y Amberes, si bien, al depender administrativamente del Principado de Lieja muestra una inclinación distintiva hacia las formas más suaves de la región del Mosa y Renania.Cfr. Comte J.de Borchgrave d'Altena, «De la place des ateliers malinois dans l'histoire de la sculpture en Belgique», B.C.A.L.A.M., LXXIX, 1975, pp. 69-80.

${ }^{87}$ D'Altena, Borchgrave, «Des caractères de la sculpture brabançonne vers 1500», Annales de la Société Royale d'Archeologie de Bruxelles, XXXVIII, 1934, pp. 11-14. Del mismo autor y con idénticas conclusiones: La Passion du Christ dans la Sculpture en Belgique du XI au XVI siècles, Bruselas, 1946, pp. 25-26. Sobre la difusión del italianismo en torno a 1510 véase, Vandeviviere, I. y Perier-d'Ieteren, Belgique Renaissante. Architecture, Art Monumental, Bruselas, 1973, pp. 17-27. La tendencia conservadora en la que se adentra la escultura de los Países Bajos a partir de 1480 ha sido estudiada recientemente por John W. Steyaert en un volumen con amplia bibliografía: «Sculpture in Tournai c. 1400-1480» en Late Gothic Sculpture. The Burgundian Netherlands, Gante, 1994, pp. 51-65.
}

$A E A$, LXXVII, 2004, 306, pp. 139 a 157 


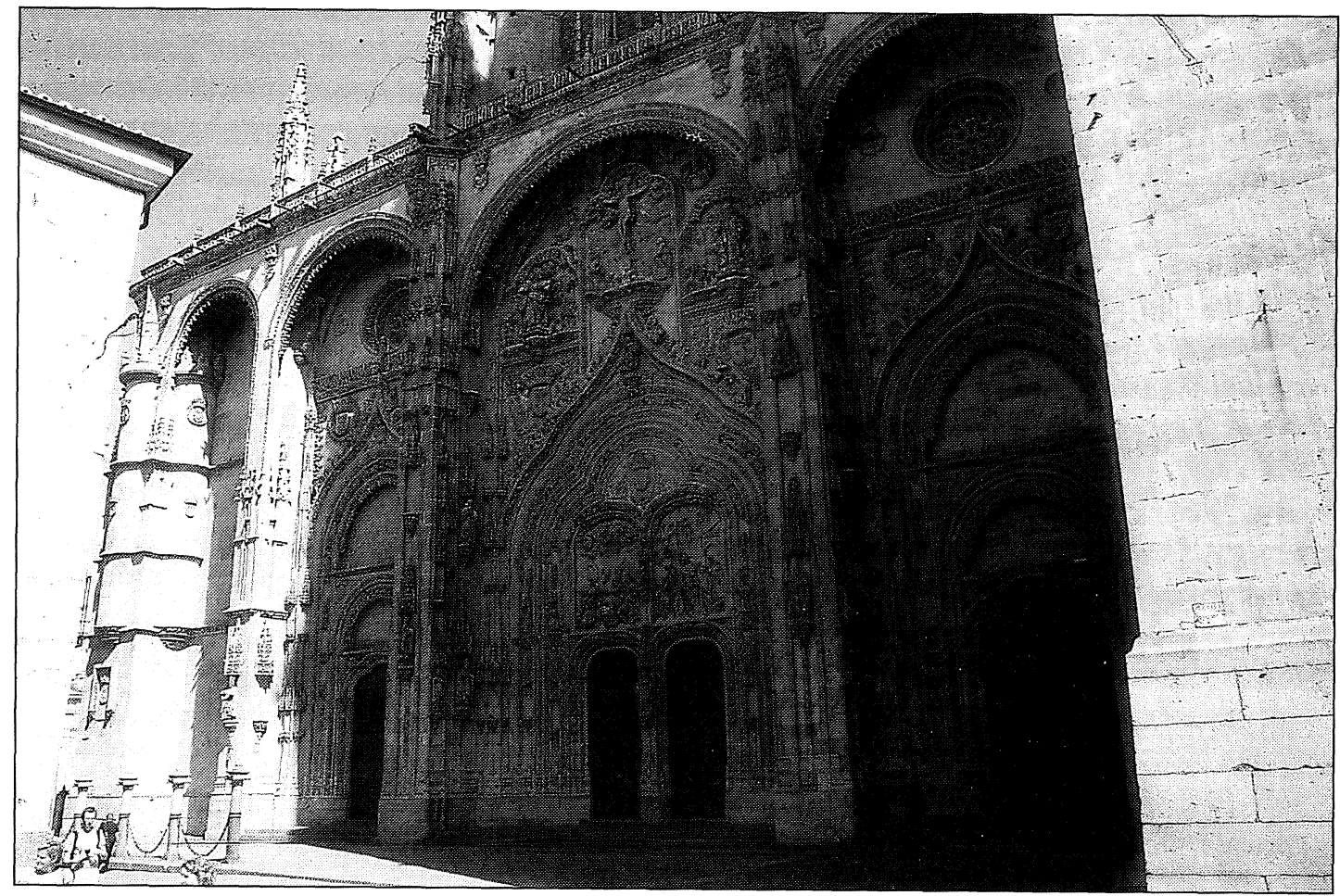

Fig. 17. Vista general de la Portada del Perdón.

el grupo de las ocho vírgenes de la rosca de los arcos carpaneles de la entrada (que la fábrica habría tenido urgencia en cubrir al encontrarse en lugar de fácil visibilidad). Y en segundo lugar, con algunas de las imágenes de santos y profetas de las dos primeras arquivoltas cuya relación con la escultura de san Adrián reside, bien en el tipo humano y la decoración vegetal de trajes y armaduras (p.e. David con la cabeza de Goliat); bien en el mismo tratamiento abultado del volumen de los hábitos, como puede verse en algunos de los santos de estas dos mismas arquivoltas (San Pedro Mártir, san Gil o San Juan de Sahagún), separados ambos grupos del calificativo de «tardogótico» que se ha empleado para definir la obra de Gil de Ronza ${ }^{88}$.

No obstante, con independencia del análisis filológico y el establecimiento de un catálogo, en estos momentos todavía imposible, la biografía del maestro Antonio tiene el interés de evidenciar que los intercambios entre las dos culturas figurativas del norte y el sur de Europa no se encuentran tan solo en las mutuas aportaciones de carácter estilístico, sino en las redes más complejas del comercio cultural (como la importación de tipos iconográficos) al que pertenece ese vasto fenómeno de la emigración artística de los Países Bajos en la España de la alta Edad Moderna.

${ }^{88}$ Rivera de las Heras, J.A., En torno al escultor Gil de Ronza, p. 7, con conclusiones diferentes de las nuestras. 